\section{Which are the most promising targets for minimal residual disease-directed therapy in acute myeloid leukemia prior to allogeneic stem cell transplant?}

\author{
Brian Ball and Eytan M. Stein \\ Memorial Sloan Kettering Cancer Center, New York, NY, USA
}

\section{ABSTRACT}

M inimal residual disease has emerged as an important prognostic factor for relapse and survival in acute myeloid leukemia. Eradication of minimal residual disease may increase the number of patients with long-term survival; however, to date, strategies that specifically target minimal residual disease are limited. Consensus guidelines on minimal residual disease detection by immunophenotypic and molecular methods are an essential initial step for clinical trials evaluating minimal residual disease. Here, we review promising targets of minimal residual disease prior to allogeneic stem cell transplantation. Specifically, the focus of this review is on the rationale and clinical development of therapies targeting: oncogenic driver mutations, apoptosis, methylation, and leukemic immune targets. We review the progress made in the clinical development of therapies against each target and the challenges that lie ahead.

\section{Introduction}

For over 45 years, standard therapy for fit patients with newly diagnosed acute myeloid leukemia (AML) has been induction chemotherapy with cytarabine and an anthracycline. ${ }^{1}$ Despite most patients achieving morphological remission with intensive chemotherapy, the prognosis for long-term survival in AML remains poor. Advances in multiparameter flow cytometry and molecular testing, including real-time quantitative polymerase chain reaction, digital polymerase chain reaction and next-generation sequencing, have enabled detection of minimal or measurable residual disease (MRD) far below a threshold of $5 \%$ blasts required for morphological remission. ${ }^{2}$ Among patients receiving induction chemotherapy, complete remission (CR) with persistent MRD occurs in a substantial $40 \%$ of patients. ${ }^{3}$ Mounting evidence has shown that the presence of MRD detectable prior to myeloablative allogeneic stem cell transplantation (SCT) is associated with shorter survival and increased risk of relapse that is similar to the risk in patients with active disease. ${ }^{4-7}$

Eradication of MRD prior to allogeneic SCT has the potential to increase longterm survival in AML. However, few studies have reported on the outcomes of patients converting from $M R D$-positive to $M R D$-negative disease after treatment with consolidation therapies. In the HOVON/SAKK AML 42A study, post-remission treatment with either chemotherapy, autologous or allogeneic SCT led to a change from MRD-positive to MRD-negative status in 7/21 (33\%) patients. ${ }^{8}$ In the GIMEMA study, late MRD clearance (induction positive, consolidation negative MRD status) was observed in 15/134 (11\%) patients and was associated with similar rates of 5-year overall survival and relapse-free survival as those of patients with early MRD clearance (induction negative, consolidation negative MRD status). MRD status after consolidation was the only factor independently associated with both a shorter duration of relapse-free survival and overall survival in multivariate analaysis, suggesting a more favorable outcome from MRD conversion after post-remission chemotherapy. ${ }^{9}$ Given the modest rates of MRD conversion with consolidation chemotherapy, more effective therapies capable of eradicating MRD prior to transplantation are urgently needed.

As a reservoir for relapse, MRD would ideally be targeted by therapies that
Haematologica 2019

Volume 104(8):1521-1531

\section{Correspondence:}

EYTAN M. STEIN

steine@mskcc.org

Received: April 15, 2019.

Accepted: July 1, 2019.

doi:10.3324/haematol.2018.208587

Check the online version for the most updated information on this article, online supplements, and information on authorship \& disclosures: www.haematologica.org/content/104/8/1521

(C)2019 Ferrata Storti Foundation

Material published in Haematologica is covered by copyright. All rights are reserved to the Ferrata Storti Foundation. Use of published material is allowed under the following terms and conditions:

https://creativecommons.org/licenses/by-nc/4.0/legalcode. Copies of published material are allowed for personal or internal use. Sharing published material for non-commercial purposes is subject to the following conditions:

https://creativecommons.org//icenses/by-nc/4.0/legalcode, sect. 3. Reproducing and sharing published material for commercial purposes is not allowed without permission in writing from the publisher. 
reduce the potential for recurrence by eliminating leukemia regenerating cells. AML is a heterogeneous disease that includes populations of bulk leukemic blasts and leukemic stem cells that are thought to be more refractory to treatment than others. ${ }^{10}$ Leukemic stem cells were initially defined phenotypically by specific cell surface markers CD34+ CD38 and functionally by an ability to initiate leukemia in animal transplant models. ${ }^{11}$ Cellular tracking of leukemic cell populations demonstrated the persistence of either leukemic stem cell subclones or more committed leukemia cells that retained stemness transcriptional programs from disease initiation to relapse. ${ }^{12}$ Therefore, central to the development of MRD targeting is the ability of the novel therapies to eradicate leukemic stem cells.

In this review, we discuss MRD targets of therapeutic potential. We focus on the therapies that have been developed for each target and, if available, evidence of efficacy in reducing $M R D$ prior to allogeneic SCT.

\section{Targeting oncogenic driver mutations}

\section{Fms-like tyrosine kinase 3 (FLT3)}

Fms-like tyrosine kinase 3 (FLT3) is the most commonly mutated gene in AML with FLT3 internal tandem duplications (ITD) and FLT3 tyrosine kinase domain (TKD) mutations occurring in $22-32 \%$ and $8 \%$ of newly diagnosed cases, respectively. ${ }^{13,14}$ In a large population-based study the incidence of FLT3-ITD mutations was lower at $18.9 \%$ and decreased with age. ${ }^{15}$ FLT3-ITD mutations are associated with worse prognosis and increased risk of relapse with allogeneic transplantation. ${ }^{13,14,16-18}$ As monotherapy, FLT3 inhibitors are capable of inducing molecular remissions and gilteritinib (Xospata) is approved for relapsed or refractory FLT3-mutated AML. ${ }^{19,20}$ Quizartinib has also demonstrated efficacy as monotherapy in patients with relapsed or refractory FLT3-ITD-mutated AML. ${ }^{21}$ The combination of FLT3 inhibitors with chemotherapy has the potential to induce deeper remissions than induction chemotherapy alone. Midostaurin (Rydapt) is a first-generation FLT3 inhibitor that was originally developed as a protein kinase $\mathrm{C}$ inhibitor and found to have inhibitory activity against multiple tyrosine kinases including FLT3. ${ }^{22}$ The phase III RATIFY trial randomized younger patients with newly diagnosed FLT3-TKD or FLT3-ITD mutated AML to midostaurin in combination with induction and consolidation chemotherapy or placebo with standard chemotherapy. Patients in the midostaurin arm had a significantly longer median overall survival (74.7 vs. 25.6 months, $P=0.009$ ) leading to approval of the regimen. In this study, MRD was not assessed; however, among patients undergoing allogeneic SCT, midostaurin in combination with chemotherapy led to a near significant increase in overall survival $(P=0.07)$ and a significant decrease in cumulative incidence of relapse [hazard ratio (HR) $0.47, P=0.02]^{23,24}$

Next-generation FLT3 inhibitors have greater specificity and higher potency. Type I inhibitors such as gilteritinib and crenolanib are active against FLT3-TKD or FLT3-ITD mutations. In contrast, FLT3-TKD mutations in the activation loop and gatekeeper domain confer resistance to type 2 inhibitors such as quizartinib. ${ }^{25}$ Active clinical trials evaluating next-generation FLT3 inhibitors in combination with induction and consolidation include NCT02283177 for crenolanib, NCT02236013 for gilteritinib, and
NCT02668653 for quizartinib. In a single-arm, phase II study (NCT02283177) of crenolanib in combination with standard induction and consolidation chemotherapy followed by crenolanib maintenance for 1 year, 24 out of 29 (83\%) patients achieved CR and 20 out of 25 evaluable patients $(80 \%)$ achieved MRD-negative disease, as determined by multiparameter flow cytometry. ${ }^{26,27}$ Similarly, in a phase I study in patients with newly diagnosed FLT3mutated AML, gilteritinib in combination with induction and consolidation led to a high CR rate of $77 \%$ $(n=23 / 30) .{ }^{28}$ A phase I study of quizartinib in combination with induction and consolidation in newly diagnosed AML led to CR in six of nine $(67 \%)$ patients and a morphological leukemia-free state in two of nine $(22 \%)$ patients with FLT3-ITD mutations. ${ }^{29}$ The high response rates of next-generation FLT3 inhibitors in combination with chemotherapy in early phase studies led to the development of randomized studies comparing gilteritinib (NCT03836209) and crenolanib (NCT02283177) to midostaurin in combination with induction and consolidation chemotherapy.

\section{Isocitrate dehydrogenases (IDH1 and IDH2)}

Mutations involving the isocitrate dehydrogenase-1 (IDH1) and -2 (IDH2) genes occur in about 6-10\% and 9$13 \%$ of newly diagnosed cases of AML, respectively. ${ }^{30-35}$ Mutant IDH has neomorphic enzyme activity leading to aberrant production of the oncometabolite 2-hydroxyglutarate. ${ }^{33,36}$ Accumulation of 2-hydroxyglutarate competitively inhibits $\alpha$-ketoglutarate-dependent enzymes including TET2, a DNA hydroxymethylase resulting in global hypermethylation, a block in cellular differentiation, an increase in self-renewal and enhancement of leukemic transformation. ${ }^{36-38}$ Ivosidenib (Tibsovo) and enasidenib (Idhifa) are oral inhibitors of mutant IDH1 and IDH2, respectively and are approved for relapsed or refractory IDH1 - and IDH2-mutant AML. ${ }^{39,40}$ In relapsed or refractory AML, ivosidenib led to clearance of IDH1 mutations in seven out of $25(28 \%)$ patients who achieved either CR or CR with incomplete count recovery (CRi). ${ }^{39}$ Similarly, treatment with enasidenib in relapsed or refractory AML led to IDH2 mutation clearance in nine out of 29 (31\%) patients achieving a CR. ${ }^{41}$ Preliminary results from a phase I study of ivosidenib or enasidenib in combination with standard induction and consolidation chemotherapy in patients with newly diagnosed IDH-mutated AML demonstrated that the combination was well tolerated. Among patients treated with ivosidinib, responses [CR, CRi or CR with imcomplete platelet recovery (CRp)] occurred in 26 out of $28(93 \%)$ and 33 out of $45(73 \%)$ patients with de novo and secondary IDH1-mutated AML, respectively. In the enasidenib group responses occurred in 33 out of $45(73 \%)$ and 20 out of $32(63 \%)$ patients with de novo and secondary IDH2-mutated AML, respectively. Furthermore, IDH-mutation clearance was observed in nine out of $22(41 \%)$ of the patients with IDH1 mutations and in 11 out of 31 (30\%) of those with IDH2 mutations. MRD negativity by multiparameter flow cytometry was observed in eight out of nine $(89 \%)$ patients with IDH1 mutations and seven out of $12(58 \%)$ of those with IDH2 mutations. ${ }^{42}$ Although IDH inhibitors and chemotherapy may increase MRD-negative rates, further studies are needed to determine the impact of the combination on survival after allogeneic SCT. A phase III, randomized study of ivosidenib or enasidenib in combination with 
induction and consolidation chemotherapy followed by maintenance therapy in newly diagnosed AML or myelodysplastic syndrome (MDS) with excess blasts-2 with an IDH1 or IDH2 mutation (NCT03839771) will soon begin enrollment.

The observation that cancer stem cells are resistant to therapies targeting BCR-ABL in chronic myeloid leukemia and JAK2 V617F in myeloproliferative neoplasms raises concern regarding the ability of targeted therapies to eradicate leukemic stem cells. ${ }^{21,22}$ If indeed FLT3 and IDH1/2 inhibitors are unable to eradicate leukemic stem cells, then targeted therapy may reduce or maintain low levels of bulk disease but will likely not be curative unless combined with allogeneic SCT or other therapies targeting leukemic stem cell. A leukemic stem cell population that is refractory to targeted therapy may also contribute to clonal evolution and the acquisition of secondary resistance mutations. Clinical studies evaluating FLT3 and IDH inhibitors as maintenance therapy after induction and consolidation and allogeneic SCT are also essential to determine the optimal duration of treatment. In the phase II AMLSG 16-10 trial, treatment with midostaurin in combination with induction and consolidation chemotherapy followed by maintenance midostaurin for 1 year after allogeneic SCT was associated with improved 1-year eventfree survival when compared to that of historical controls with FLT3-ITD-mutated AML [HR 0.58; 95\% confidence interval (95\% CI): 0.48-0.7; $P<0.001]$. $^{43}$

\section{Targets of apoptosis evasion}

\section{B-cell lymphoma 2 (BCL2)}

Evasion of apoptosis is a hallmark of malignant tumor progression, allowing for tumor survival and resistance to cancer treatments. ${ }^{37}$ The anti-apoptotic protein B-cell lymphoma 2 (BCL2) is overexpressed in AML and associated with resistance to chemotherapy and poor outcomes. ${ }^{44}$ The prosurvival BCL2 family of proteins such as BCL2 and MCL1 sequester the apoptosis initiator protein BIM to prevent initiation of apoptosis. ${ }^{45}$ Aberrant BCL2 expression is also essential for maintaining oxidative phosphorylation in quiescent leukemic stem cells. BCL2 inhibition reduces oxidative phosphorylation and preferentially induces cell death in leukemic stem cells. ${ }^{46,47}$

Venetoclax is an oral, BH3 mimetic that selectively binds BCL2, displacing pro-apoptotic proteins leading to apoptosis. ${ }^{48}$ Monotherapy with venetoclax demonstrated clinical activity in early phase studies but was associated with modest response rates and a short duration of response. ${ }^{49}$ Combinations of venetoclax with both lowdose cytarabine and hypomethylating agents in previously untreated, newly diagnosed elderly patients not eligible for chemotherapy resulted in high response rates and durable remissions leading, to Food and Drug Administration (FDA) approval of these regimens.,50,51 Venetoclax and hypomethylating agents led to a CR or CRi with MRD-negative disease by multiparameter flow cytometry in $45 \%$ of patients. ${ }^{52}$ Similarly, treatment with venetoclax and low-dose cytarabine led to MRD-negative disease in $32 \%$ of patients in CR or CRi..$^{53}$ This spurred the development of trials evaluating venetoclax in combination with 7+3 (NCT03709758), CPX-351 (NCT03629171), or FLAG-IDA (NCT03214562) based induction regimens in newly diagnosed patients eligible for chemotherapy. In a phase I study of venetoclax in combination with FLAGIDA in relapsed or refractory AML, treatment was well tolerated and eight of 11 patients achieved a CR or CRi. ${ }^{54}$ The high MRD-negative rates associated with venetoclax combinations are encouraging; however, additional phase III studies are needed to determine if there is a survival benefit, in particular among patients who undergo allogeneic SCT.

\section{Tumor protein 53 (TP53)}

p53 is a transcription factor that is activated by cellular stress and promotes cell cycle arrest, senescence and apoptosis. ${ }^{55}$ Loss of p53 induces oncogenic self-renewal in mouse hematopoietic progenitor cells. ${ }^{56}$ In AML, inactivating mutations in the TP53 gene occur in $7-18 \%$ of patients with newly diagnosed AML and are enriched in patients with other poor prognostic features including complex karyotype and therapy-related disease. ${ }^{57,58}$ The co-occurrence of TP53 mutations and a complex karyotype is associated with an especially dismal prognosis and a high rate of relapse after allogeneic SCT. ${ }^{59}$ In AML, p53 inactivation more commonly results from overexpression of negative regulators. ${ }^{60,61} \mathrm{MDMX}$ and $\mathrm{MDM} 2$ inhibit p53 transactivation and induce its ubiquitination with subsequent degradation. ${ }^{62}$ Idasanutlin is an oral selective MDM2 inhibitor capable of activating apoptosis in a p53-dependent manner. ${ }^{63}$ Current trials evaluating the combination of this MDM2 inhibitor with chemotherapy include a phase I/II study (NCT03850535) of idasanutlin in combination with standard induction chemotherapy in newly diagnosed AML and a phase III study (NCT02545283) of idasanutlin with or without cytarabine in relapsed or refractory AML.

Despite many patients achieving deep and durable remissions with apoptosis inhibitors, primary and secondary resistance is known to occur. In particular, RAS pathway mutations and TP53 mutations are associated with decreased responses to venetoclax. ${ }^{47,51,64,65}$ MCL-1 also serves as a redundant pro-survival pathway that mediates resistance to venetoclax. ${ }^{48,49}$ In cell lines resistant to BCL2 inhibition, idasanutlin led to induction of apoptosis through p53 activation and MCL1 degradation. ${ }^{52}$ MCL1 mimetics currently in active trials as monotherapy and in combination with venetoclax include S64315 (Servier) (NCT02979366, NCT03672695), AMG 176 (Amgen) (NCT02675452, NCT03797261), and AMG 397 (Amgen) (NCT03465540). Additionally, TP53-mutant AML are resistant to $\mathrm{MDM} 2$ inhibitors and prolonged exposure to idasanutlin in cancer cell lines has been associated with the development of TP53 mutations. APR-246 is a prodrug that is converted to the Michael acceptor methylene quinuclidinone, which covalently binds mutated p53 cysteine residues 124 and 277, leading to refolding and restoration of p53 function. ${ }^{66,67}$ In a phase Ib study of APR-246 in combination with azacitidine in patients with TP53-mutant MDS and AML, all 11 evaluable patients responded with nine patients achieving CR (82\%) and eight having clearance of p53 mutations (73\%). ${ }^{68}$

\section{Methylation}

The hypomethylating agents 2'deoxy-5-azacitidine (decitabine) and 5-azacitidine (azacitidine) are approved for the treatment of MDS and newly diagnosed AML patients unfit for chemotherapy. ${ }^{69-71}$ Azacitidine and 
decitabine are nucleoside analogs that irreversibly bind the methylase DNMT1 leading to global hypomethylation, resulting in altered expression and cell death. ${ }^{72,73}$ Low doses of hypomethylating agents disrupt immune evasion by inducing expression of tumor-associated antigens such as cancer/testis antigens in AML cell lines and antigen presentation molecules such as human leukocyte antigen class I antigens. ${ }^{7477}$ Hypomethylating agents also upregulate expression of endogenous retroviruses that activate viral recognition and interferon response pathways. ${ }^{78,79}$ In contrast, treatment with hypomethylating agents induced expression of programmed cell death protein 1 (PD1), programmed death-ligand 1 and 2 (PD-L1 and PD-L2) and cytotoxic T-cell ligand antigen 4 (CTLA-4) in patients with MDS, AML and chronic myelomonocytic leukemia and was associated with resistance to treatment with hypomethylating agents. ${ }^{80}$

In the RELAZA2 trial, patients with advanced MDS or AML who achieved a CR after conventional chemotherapy or allogeneic SCT but had MRD, detected by either quantitative polymerase chain reaction for mutant NPM1 or other leukemia-specific fusion genes or by flow cytometry, were treated with azacitidine. ${ }^{81}$ The study met its primary endpoint with 31 out of $53(58 \%)$ patients being relapse-free at 6 months. Reassessment of MRD status revealed that 19 out of 53 patients achieved MRD negativity and 12 out of $19 \mathrm{MRD}$-negative patients maintained MRD negativity without hematologic relapse during the median follow-up time of 23 months. Post-hoc analysis demonstrated a difference in relapse-free survival (HR 0.2, $P<0.0001$ ), but not overall survival (HR 0.4, $P=0.112$ ), between responders and non-responders to azacitidine. ${ }^{81}$

\section{Immunotherapy targets}

Immunotherapy is an approach that uses the potency of the immune system as a therapeutic modality against cancer. $^{82,83}$ The rationale for immunotherapy in AML lies in the curative potential of allogeneic SCT as post-remission therapy mediated by a graft-versus-leukemia effect. Similarly, immunotherapy leverages the adaptive immune system, specifically antibodies from B cells and the T-cell receptor on $\mathrm{T}$ cells to recognize antigens expressed on the cancer cells. In AML, immunotherapy has the potential to target unique leukemic stem cell surface antigens, thereby selectively eradicating these cells.

\section{Immune checkpoints: PD1, PD-L1, CTLA-4}

Immune modulating antibodies against negative regulators of T-lymphocyte activation, including anti-CTLA-4 and anti-PD1/PD-L1 have produced unprecedented rates of durable responses in a variety of malignancies. ${ }^{83}$ In AML, responses to checkpoint inhibitors as monotherapy have been modest. A phase I study of patients treated with the anti-PD1 antibody pidilizumab revealed a response in only one out of eight patients with AML with a reduction in blast percentages from $50 \%$ to $5 \% .{ }^{84} \mathrm{~A}$ phase I/Ib study of 28 patients with relapsed hematologic malignancies after allogeneic transplantation, including 12 patients with AML, evaluated the anti-CTLA-4 antibody ipilimumab, given at doses of $3 \mathrm{mg} / \mathrm{kg}$ and $10 \mathrm{mg} / \mathrm{kg}$. Responses were only observed with the ipilimumab 10 $\mathrm{mg} / \mathrm{kg}$ dose in seven out of $22(32 \%)$ patients and included $\mathrm{CR}$ in four patients with extramedullary AML and one patient with MDS that progressed to AML. Dose-limiting chronic graft-versus-host disease of the liver or gut occurred in four patients but resolved when the treatment was withheld and steroids were administered. ${ }^{85}$ Active phase II studies evaluating anti-PD1 therapy as postremission treatment include NCT02532231 with nivolum$\mathrm{ab}$ and NCT02708641 with pembrolizumab.

In order to enhance responses to checkpoint inhibition in AML, combinations with chemotherapy, hypomethylating agents, and other checkpoint inhibitors are under investigation. In a phase II study (NCT02464657) patients with newly diagnosed AML received induction chemotherapy with idarubicin and cytarabine followed by nivolumab $3 \mathrm{mg} / \mathrm{kg}$ starting on day 24 and continued every 2 weeks for up to 1 year; 34 out of 44 patients (77\%) achieved a CR or CRi and 18 out of $43(53 \%)$ had undetectable MRD by multiparameter flow cytometry. Responses were durable and the median overall survival was 18.5 months, which compared favorably to that of a contemporary cohort of patients treated with idarubicin and cytarabine induction alone. Among 18 patients who underwent allogeneic SCT, 13 (72\%) developed graft-versus-host disease and eight responded to treatment. ${ }^{86}$ Increased expression of PD1, PD-L1, and CTLA-4 is associated with resistance to treatment with hypomethylating agents but has the potential to sensitize leukemia cells to checkpoint-blocking monoclonal antibodies. ${ }^{74,80}$ In a phase II study of azacytidine and nivolumab $3 \mathrm{mg} / \mathrm{kg}$ on days 1 and 14 in relapsed/refractory AML, responses occurred in 23 patients (overall response rate, 33\%) including 15 patients $(22 \%)$ with CR or CRi. The median overall survival for all patients enrolled was 6.3 months, while that of the patients who achieved any type of response (CR, CRi, partial response or hematologic improvement) or had stable disease was 16.2 months. When compared to controls from historical hypomethylating agent-based clinical trials, patients receiving nivolumab and hypomethylating agents had an increased response rate (33\% vs. 20\%) and significantly longer median overall survival (6.3 vs. 4.6 months). ${ }^{87}$ The phase II PEMAZA study is evaluating azacitidine in combination with pembrolizumab in patients achieving CR after induction chemotherapy but with detectable MRD (NCT03769532).

\section{Dendritic cells}

Dendritic cells are the most potent antigen-presenting cells capable of priming new responses or enhancing existing antigen-specific immune responses. ${ }^{88,89}$ Mature dendritic cells facilitate cytotoxic T-lymphocyte activation through antigen presentation on major histocompatibility complex class 1 molecules, termed cross-presentation and by upregulating co-stimulatory molecules, such as CD80 and CD86..$^{89,90}$ Dendritic cell vaccination approaches differ in the source of dendritic precursors, maturation methods, target antigen, antigen loading, and in the administration of the vaccine. ${ }^{89}$ A phase II study of patients with AML in first CR after induction chemotherapy at high risk for relapse and without a matched sibling donor for allogeneic hematopoietic SCT revealed that treatment with WT1 mRNA-electroporated dendritic cell vaccine led to a clinical response in 13 out of 30 patients (30\%) with nine patients achieving molecular remission by WT1 transcript levels. ${ }^{91}$ The 5 -year overall survival rate was $40 \%$ among vaccine recipients and compared favorably to a 5 -year overall survival rate of $24.7 \%$ observed in historical con- 
trols. $^{91}$ Additionally, the dendritic cell vaccine elicited WT1-specific $\mathrm{CD}^{+} \mathrm{T}$-cell responses resulting in expression that correlated with long-term survival. ${ }^{91}$ Another prospective study of a vaccine composed of patientderived AML cells fused with autologous dendritic cells in patients in CR after induction chemotherapy not eligible for allogeneic SCT led to sustained remission in 12 of 17 patients receiving at least one dose of vaccine and a 4-year progression-free survival rate of $71 \%$ : the median progression-free and overall survival had not been reached. ${ }^{92}$ The vaccine was well tolerated with the most common adverse events being erythema, pruritis and/or induration at the vaccine site. ${ }^{2}$ The dendritic cell/AML fusion also induced $\mathrm{CD}^{+} \mathrm{T}$-cell specific responses and an increased circulating leukemia-reactive $\mathrm{T}$-cell population that persisted for more than 6 months. ${ }^{92}$

\section{Antibody drug conjugates and bispecific T-cell engaging therapy}

\section{Cluster of differentiation 33 (CD33)}

The development of an antibody-based therapy targeting antigens expressed on leukemic blasts to eradicate MRD is supported by the efficacy of the CD19/CD3 bispecific antibody, blinatumomab in B-cell acute lymphoblastic leukemia. ${ }^{73} \mathrm{CD} 33$ is a transmembrane sialic acid-binding immunoglobulin-like lectin (SIGLEC) family protein that is expressed by cells of the myeloid lineage but not hematopoietic stem cells. ${ }^{93-95} \mathrm{CD} 33$ is expressed on leukemic blasts as well as CD34+CD38 leukemic stem cells. ${ }^{96}$ CD33 levels are highest in acute promyelocytic leukemia and AML with NPM1, FLT3-ITD and KMT2A mutations and lower in those with core-binding factor translocations or complex cytogenetics. ${ }^{97}$ Gemtuzumab ozogamicin (GO) is a human antibody conjugated to a
DNA-damaging calicheamicin derivative by an acid-labile linker. ${ }^{98}$ Based on promising results from three single-arm phase II studies at a dose of $9 \mathrm{mg} / \mathrm{m}^{2}$ given every 2 weeks, GO was initially granted FDA approval for patients $>60$ years of age with $\mathrm{CD} 33^{+} \mathrm{AML}$ who were not candidates for aggressive chemotherapy.9 ${ }^{99}$ However, GO was later withdrawn from the commercial market in October 2010 after the confirmatory phase III SWOG S0106 study showed no survival benefit and increased treatment-related mortality in patients treated with GO compared to those given standard induction. ${ }^{100}$ Subsequent studies have evaluated reduced and fractionated dosing of GO to decrease treatment-related toxicity. ${ }^{100-103}$ A large meta-analysis from five randomized controlled trials of patients with newly diagnosed AML receiving GO with induction chemotherapy revealed that the addition of $\mathrm{GO}$ was associated with a reduced risk of relapse (odds ratio $0.81, P=0.0001$ ) and improved overall survival at 5 years (odds ratio $0.9, P=0.01$ ), especially in patients with favorable and intermediate-risk cytogenetics. ${ }^{104}$ Additionally, the NCRI AML17 trial demonstrated a lower rate of veno-occlusive disease and early mortality but no difference in relapse or survival at 4 years between patients given $\mathrm{GO}$ at a dose of $3 \mathrm{mg} / \mathrm{m}^{2}$ or a dose of $6 \mathrm{mg} / \mathrm{m}^{2}$. ${ }^{105}$ As a result $\mathrm{GO}$ received FDA approval for adults with newly diagnosed AML, whose tumor expresses the CD33 antigen. Retrospective analysis of adult patients with NPM1-mutated AML enrolled in the ALFA-0701 trial revealed that $\mathrm{GO}$ in combination with induction chemotherapy increased the proportion of patients with $M R D$-negative disease at the end of treatment, as determined by NPM1 gene transcript levels, when compared to those treated with chemotherapy alone $(91 \%$ vs. $61 \%$, $P=0.028){ }^{106}$ This has led to a phase II trial of fractionated GO on days 1, 4, and 7 in patients with MRD after at least one cycle of induction chemotherapy. (NCT03737955)

\section{Clinical trials evaluating MRD-directed therapies}

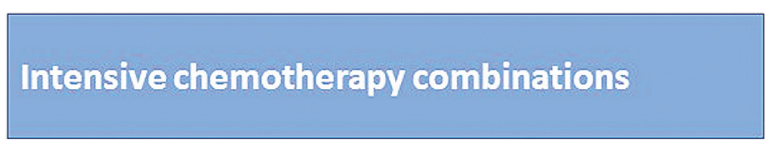

\begin{tabular}{|l|l|}
\hline Target & Therapy (Clinical trial ID) \\
\hline FLT3 ITD/TKD & Gilteritinib (NCT02236013, NCT03836209) \\
FLT3 ITD/TKD & Crenolanib (NCT02236013, NCT03258931) \\
FLT3 ITD & Quizartinib (NCT02668653) \\
IDH1/IDH2 & Ivosidenib or enasidenib (NCT03839771) \\
IDH2 & Enasidenib (NCT03825796) \\
BCL2 & Venetoclax (NCT03709758, NCT03214562, \\
MDM2 & Idasanutlin (NCT03850535, NCT02545283) \\
PD1 & Nivolumab (NCT02464657) \\
PD1 & Pembrolizumab (NCT02768792) \\
CD33 & $\begin{array}{l}\text { Gemtuzumab (NCT03531918, NCT00801489, } \\
\text { NCT03839446, NCT03900949, NCT03904251) }\end{array}$ \\
\hline
\end{tabular}

\section{Non-chemotherapy post-remission therapies}

\begin{tabular}{|l|l|}
\hline Target & Therapy (Clinical trial ID) \\
\hline PD1 & $\begin{array}{l}\text { Pembrolizumab + azacitidine } \\
\text { (NCT03769532) }\end{array}$ \\
PD1 & Pembrolizumab (NCT02708641) \\
PD1 & Nivolumab (NCT02532231) \\
WT1 & WT1 mRNA DC vaccine (NCT01686334) \\
AML antigens & DCP-001 DC vaccine (NCT03697707) \\
AML antigens & DC/ AML cell fusion vaccine \\
CD33 & (NCT03059485) \\
CD123 & Gemtuzumab (NCT03737955) \\
\hline
\end{tabular}

Figure 1. Active clinical trials evaluating minimal residual disease-directed therapies arranged by trial design. Trials with induction and consolidation-based combinations are shown on the left, non-chemotherapy post-remission therapies are shown on the right. Studies evaluating post-allogeneic transplant minimal residual disease therapies are not included. 
Table 1. Outcomes of clinical trials targeting minimal residual disease with induction chemotherapy or as post-remission therapy.

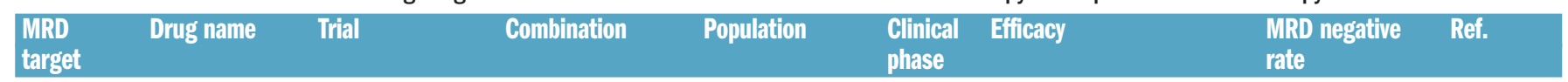

\begin{tabular}{|c|c|c|c|c|c|c|}
\hline $\begin{array}{l}\text { FLT3 TKD } \\
\text { FLT3 ITD }\end{array}$ & $\begin{array}{l}\text { Gilteritinib } \\
\text { (ASP 2215) }\end{array}$ & NCT02236013 & $\begin{array}{l}\text { Gilteritinib } \\
\text { with induction }\end{array}$ & $\begin{array}{l}\text { Newly } \\
\text { diagnosed }\end{array}$ & I & $\begin{array}{l}\text { Among FLT3 mutated } \\
\text { patients: CR 23/30 (77\%) }\end{array}$ \\
\hline
\end{tabular}

and consolidation AML

$\mathrm{CRc}(\mathrm{CR} / \mathrm{CRp} / \mathrm{CRi})$

chemotherapy

\begin{tabular}{|c|c|c|c|c|c|c|c|c|}
\hline $\begin{array}{l}\text { FLT3 TKD } \\
\text { FLT3 ITD }\end{array}$ & Crenolanib & NCT02283177 & $\begin{array}{l}\text { Crenolanib with } \\
\text { induction and } \\
\text { consolidation } \\
\text { chemotherapy }\end{array}$ & $\begin{array}{l}\text { Newly } \\
\text { diagnosed } \\
\text { FLT3-mutated } \\
\text { AML }\end{array}$ & II & $\begin{array}{l}\text { CR 24/ } 29 \text { (83\%) } \\
2 \text { patients relapsed } \\
\text { with a median } \\
\text { follow-up of } 14 \text { months }\end{array}$ & $\begin{array}{l}20 / 25(80 \%) \\
\text { by MPFC }\end{array}$ & $(26,27)$ \\
\hline FLT3 ITD & Quizartinib & NCT01892371 & $\begin{array}{l}\text { Quizartinib with } \\
\text { induction and } \\
\text { consolidation } \\
\text { chemotherapy }\end{array}$ & $\begin{array}{l}\text { Newly } \\
\text { diagnosed } \\
\text { AML }\end{array}$ & I & $\begin{array}{l}\text { Among FLT3-ITD } \\
\text { mutated patients } \\
\text { CR 6/9 (67\%) } \\
\text { MLFS 2/9 (22\%) }\end{array}$ & Not reported & (29) \\
\hline $\begin{array}{l}\text { IDHI } \\
\text { IDH2 }\end{array}$ & $\begin{array}{l}\text { Ivosidenib } \\
\text { Enasidenib }\end{array}$ & NCT02632708 & $\begin{array}{l}\text { Ivosidenib or } \\
\text { enasidenib in } \\
\text { combination with } \\
\text { induction and } \\
\text { consolidation } \\
\text { chemotherapy }\end{array}$ & $\begin{array}{l}\text { Newly } \\
\text { diagnosed AML } \\
\text { with an } I D H 1 \\
\text { and/or IDH2 } \\
\text { mutation }\end{array}$ & I & $\begin{array}{l}\text { Ivosidenib } \\
\text { De novo AML } \\
\text { CRc (CR, CRi, CRp) } \\
\text { 26/28 (93\%) } \\
\text { Secondary AML } \\
\text { CRc 6/13 (46\%) } \\
\\
\text { Enasidenib De novo } \\
\text { AML CRc 33/45 (73\%) } \\
\text { Secondary AML } \\
\text { CRc 20/32 (63\%) }\end{array}$ & $\begin{array}{l}\text { IDH1 MC: } 9 / 22 \\
(41 \%) \text { of } \\
\text { responding } \\
\text { patients by NGS } \\
I D H 2 \mathrm{MC}: 11 / 37 \\
(30 \%) \text { of } \\
\text { responding } \\
\text { patients by NGS }\end{array}$ & (42) \\
\hline BCL-2 & Venetoclax & NCT03214562 & $\begin{array}{l}\text { Venetoclax in } \\
\text { combination } \\
\text { with FLAG-IDA }\end{array}$ & $\begin{array}{l}\text { Relapsed or } \\
\text { refractory AML }\end{array}$ & I & CR+CRi 8/11 (73\%) & Not reported & (54) \\
\hline DNMT1 & Azacitidine & NCT01462578 & None & $\begin{array}{l}\text { Advanced MDS } \\
\text { or AML in CR, } \\
\text { MRD+ after } \\
\text { induction or } \\
\text { allo-SCT }\end{array}$ & $\mathrm{I} / \mathrm{II}$ & $\begin{array}{l}\text { Primary endpoint: } \\
\text { relapse-free at } \\
6 \text { months } \\
\text { post- treatment } \\
31 / 53(58 \%)\end{array}$ & $\begin{array}{l}\text { 19/53 (36\%) by } \\
\text { NPM1 or fusion } \\
\text { gene transcript } \\
\text { levels }\end{array}$ & (81) \\
\hline PD1 & Nivolumab & NCT02464657 & $\begin{array}{l}\text { Nivolumab in } \\
\text { combination } \\
\text { with standard } \\
\text { induction and }\end{array}$ & $\begin{array}{l}\text { High-MDS } \\
\text { or AML, } \\
\text { chemotherapy } \\
\text { naïve }\end{array}$ & II & CR+CRi 34/44 (77\%) & $\begin{array}{l}18 / 34(53 \%) \\
\text { by MPFC after } \\
\text { induction }\end{array}$ & (86) \\
\hline
\end{tabular}

consolidation chemotherapy

AMG 330 is a bispecific T-cell engager (BiTE) antibody construct that binds CD33 on leukemic blasts and CD3 on $\mathrm{T}$ cells. ${ }^{107}$ Preliminary results from a phase I study (NCT02520427) of AMG330, revealed serious adverse events in 23 out of 35 patients $(66 \%)$ including cytokine release syndrome in 11 patients. The cytokine release syndrome was mitigated with step-up dosing, corticosteroid pretreatment, intravenous fluids, tocilizumab, and drug interruption. Two patients had a CR and two had a CRi during dose escalation. ${ }^{108}$

\section{Cluster of differentiation 123 (CD123)}

CD123 is the alpha chain of the interleukin-3 receptor heterodimer and is expressed at higher levels in leukemic stem cells than on normal hematopoietic bone marrow stem cells. ${ }^{109,10} \mathrm{CD} 123^{+} \mathrm{CD} 34^{+} \mathrm{CD} 38$ leukemic cells are capable of initiating and maintaining leukemia in NOD/SCID mice. ${ }^{110}$ IMGN632 is a CD123 targeting antibody-drug conjugate consisting of a CD123 antibody linked to a DNA alkylating indolino-benzodiazepine dimer (IGN) via a protease cleavable linker. ${ }^{11}$ In a phase I trial of IMGN632 (NCT03386513) in patients with relapsed or refractory $\mathrm{CD} 123^{+}$hematologic malignancies, four out of $12(33 \%)$ patients with AML achieved a CR or CRi. ${ }^{12}$ Elzonris (tagraxofusp or SL-401) is a recombinant fusion protein consisting of human interleukin-3 fused via a Met-His linker to a truncated diptheria toxin that is currently FDA-approved for the treatment of blastic plasmacytoid dendritic-cell neoplasm. . $^{11,114}$ The interleukin-3 domain binds to the interleukin-3 receptor leading to translocation of the diphtheria A fragment and thus to inactivation of protein synthesis and cell death. A phase I/II study of SL-401 as consolidation therapy for patients in first or second CR is ongoing. (NCT02270463)

\section{C-type lectin-like molecule-1 (CLL1 or CLEC12A)}

C-type lectin-like molecule-1 (CLL1 or CLEC12A) is a transmembrane glycoprotein that functions as an inhibitory receptor. CLL-1 is expressed on leukemic blasts in the majority of cases and selectively expressed in leukemic CD34 CD38 cells but not normal hematopoietic stem cells. Moreover, $\mathrm{CLL}_{1}^{+} \mathrm{CD} 34^{+}$cells are serially trans- 


\begin{tabular}{|c|c|c|c|c|c|c|c|c|}
\hline $\begin{array}{l}\text { MRD } \\
\text { target }\end{array}$ & Drug name & Trial & Combination & Population & $\begin{array}{l}\text { Clinical } \\
\text { phase }\end{array}$ & Efficacy & $\begin{array}{l}\text { MRD negative } \\
\text { rate }\end{array}$ & Ref. \\
\hline $\begin{array}{l}\text { Dendritic } \\
\text { cells }\end{array}$ & $\begin{array}{l}\text { WT1- mRNA } \\
\text { dendritic cells }\end{array}$ & NCT00965224 & None & $\begin{array}{l}\text { AML or } \\
\text { MDS RAEB1/2 } \\
\text { in PR or CR or } \\
\text { smoldering course } \\
\text { with high risk } \\
\text { of relapse }\end{array}$ & II & $\begin{array}{l}\text { Clinical response } \\
\text { rate } 13 / 30(43 \%) \\
5 \text {-year OS } 40 \% \\
\text { vs. } 24.7 \% \text { historical } \\
\text { control }\end{array}$ & $\begin{array}{l}9 / 30(30 \%) \\
\text { by WT1 } \\
\text { transcript } \\
\text { levels }\end{array}$ & (91) \\
\hline $\begin{array}{l}\text { Dendritic } \\
\text { cells }\end{array}$ & $\begin{array}{l}\text { hTERT- } \\
\text { dendritic cells }\end{array}$ & NCT00510133 & None & $\begin{array}{l}\text { AML in first or } \\
\text { second CR after } \\
\text { induction or } \\
\text { consolidation }\end{array}$ & II & $\begin{array}{l}\text { Recurrence free } \\
\text { at a median } 52 \\
\text { months follow up } \\
11 / 19(74 \%)\end{array}$ & Not reported & (125) \\
\hline $\begin{array}{l}\text { Dendritic } \\
\text { cells }\end{array}$ & $\begin{array}{l}\mathrm{AML} / \text { dendritic } \\
\text { cell fusion }\end{array}$ & NCT01096602 & None & $\begin{array}{l}\text { Newly diagnosed } \\
\text { or first relapsed } \\
\text { AML in CR } \\
\text { ineligible for allo-SC }\end{array}$ & & $\begin{array}{l}\text { 4-year progression- } \\
\text { free survival } 71 \%\end{array}$ & Not reported & (92) \\
\hline $\begin{array}{l}\text { Dendritic } \\
\text { cells }\end{array}$ & $\begin{array}{l}\text { DCPrime } \\
\text { (DCP-001) }\end{array}$ & NCT00965224 & None & $\begin{array}{l}\text { AML in CR after } \\
\geq 1 \text { course of } \\
\text { chemotherapy } \\
\text { and age }>60 \text { years } \\
\text { or }<60 \text { years } \\
\text { without allo-SCT do }\end{array}$ & $\begin{array}{l}\text { II } \\
\text { onor }\end{array}$ & $\begin{array}{l}\text { Clinical response } \\
\text { rate } 12 / 20(43 \%) \\
5 \text {-years OS } 40 \%\end{array}$ & $\begin{array}{l}9 / 13 \text { by } \\
\text { normalization } \\
\text { of } W T 1 \text { transcript } \\
\text { levels }\end{array}$ & (126) \\
\hline CD33 & $\begin{array}{l}\text { Gemtuzumab } \\
\text { ozoganicin }\end{array}$ & NCT00927498 & $\begin{array}{l}\text { GO in } \\
\text { combination with } \\
\text { standard induction } \\
\text { and consolidation }\end{array}$ & $\begin{array}{l}\text { Untreated } \\
\text { de novo AML }\end{array}$ & III & $\begin{array}{l}\text { GO vs. control } \\
\text { Median as: } \\
27.5 \text { vs. } 21.8 \text { months } \\
(P=0.16) \\
\text { Median event-free } \\
\text { survival: } 17.3 \text { vs. } 9.5 \\
\text { months }(P<0.01)\end{array}$ & $\begin{array}{l}\text { Post- induction } \\
\text { GO vs. control } \\
39 \% \text { vs. } 7 \%, P<0.01 \\
\text { Post-treatment } \\
\text { GO vs. control } \\
91 \% \text { vs. } 61 \%, P=0.03 \\
\text { by NPM1 mutation } \\
\text { transcript levels }\end{array}$ & $(106,127)$ \\
\hline
\end{tabular}

MRD: minimal residual disease; Ref.: references; FLT3 TKD: fms-like tyrosine kinase 3 (FLT3) gene tyrosine kinase domain mutations; FLT3 ITD: FLT3 internal tandem duplications; AML acute myeloid leukemia; CR: complete remission; CRi: complete remission with incomplete count recovery; CRp: complete remission with incomplete platelet recovery; CRc: complete remission - composite; MPFC: multiparameter flow cytometry; MLFS: morphological leukemia-free state; IDH1/ IDH2: isocitrate dehydrogenase-1 and -2; MC: mutation clearance; NGS: nextgeneration sequencing; BCL-2: B-cell lymphoma-2; FLAG-IDA: fludarabine, cytarabine, idarubicin, and granulocyte colony-stimulating factor; DNMT1: DNA methyltransferase 1; allo-SCT: allogeneic stem cell transplant; $N P M 1$ : nucleophosmin 1; PD1: programmed death protein 1; MDS: myelodysplastic syndrome; WT1: Wilms tumor 1; RAEB 1/2: refractory anemia with excess blasts; PR: partial response; OS: overall survival; hTERT: human telomerase reverse transcriptase; GO: gemtuzumab ozogamicin

plantable in NOD/SCID mice suggesting a self-renewal ability. ${ }^{115}$ MCLA-117 is a potent bispecific T-cell engager that directs $\mathrm{CD}^{+} \mathrm{T}$ cells to leukemia cells expressing CLL1. ${ }^{16}$ A phase I clinical trial of MCLA-117 in patients with relapsed or refractory AML or in elderly patients not eligible for chemotherapy is currently recruiting patients (NCT03038230).

\section{Chimeric antigen receptor therapy}

Chimeric antigen receptors (CAR) are engineered extracellular receptors joined to intracellular signaling domains that reprogram immune cells for therapeutic purposes. ${ }^{117}$ The development of second-generation CAR with an additional CD28 or $41 \mathrm{BB}$ co-stimulatory domain has allowed for effective responses. ${ }^{17}$ CAR-T cells kill tumor cells and promote immune surveillance directly by persisting and indirectly by cross-priming tumor-infiltrating lymphocytes through antigen release. ${ }^{10-12}$ CAR therapy targeting CD19 is extremely effective in B-cell malignancies, resulting in the approval of tisagenlecleucel (Kymriah) for the treatment of pediatric B-cell acute lymphoblastic leukemia that is refractory or in second relapse and axicabtagene ciloleucel (Yescarta) in large B-cell lymphomas after two or more lines of systemic therapy.

A phase I study of autologous CAR-T cells with speci- ficity for a difucosylated carbohydrate antigen Lewis (Le)Y coupled to the cytoplasmic domains of CD28 and TCR$\zeta$ chain produced a transient cytogenetic remission in one out of three patients with MRD at the time of infusion. Another patient with MRD prior to the infusion of CAR$T$ cells had persistent cytogenetic MRD but sustained MRD negativity by multiparameter flow cytometry for 23 months. Although LeY CAR-T cells persisted up to 10 months after infusion, most patients relapsed within the first 5 months suggesting possible antigen escape. None of the patients developed grade 3 or 4 toxicity. ${ }^{118}$

In AML, the ideal CAR target that is highly expressed in myeloid blasts and spares normal myeloid progenitor cells and vital tissues has not yet been identified. In preclinical studies anti-CD33 CAR-T cells resulted in a reduction of normal myeloid progenitors. ${ }^{119,120}$ Similarly, anti-CD123 CAR-T cells have demonstrated myeloablation in a xenograft mouse model. ${ }^{121}$ CLL1 CAR-T cells are cytotoxic to normal mature myeloid cells but not to normal myeloid progenitor cells or hematopoietic stem cells. ${ }^{122}$ An extensive proteomic and transcriptomic analysis revealed four potential CAR targets, ADGRE2, CCR1, CD70, and LILRB2, with high expression in AML, AML leukemic stem cells, and low expression in normal tissues, normal hematopoietic stem and progenitor cells and resting/acti- 
vated $\mathrm{T}$ cells. However, none of the targets showed a profile comparable with that of CD19 in B-cell malignancies. ${ }^{123}$ This suggests that combinatorial strategies may be necessary for targeting AML with CAR-T cells. An approach for combination includes bispecific T cells that co-express two CAR or a dual-specific CAR (CAR/CAR T cells) allowing T-cell recognition of target cells that express any of two given antigens. ${ }^{123}$ Alternatively, the combination of a CAR that alone is insufficient to activate a T cell and a chimeric co-stimulatory receptor (CAR/CCR T cells) restricts T-cell recognition to dual antigen-expressing target cells. The latter approach requires pan-expression of CAR targets on AML cells, which was not seen by Perna and colleagues. ${ }^{117}$ Persistent CAR-T-cell mediated myelotoxicity may necessitate incorporation of CAR-T cells with conditioning regimens prior to allogeneic SCT. An alternative approach currently in development is the use of genetically modified donor allografts that lack expression of CAR-T-cell targets, such as CD33, followed by administration anti-CD33 CAR-T cells after transplantation. ${ }^{124}$

\section{Conclusion}

Advancements in flow cytometry, quantitative polymerase chain reaction analysis and more recently nextgeneration sequencing continue to push the limits of detection of residual disease and open the door to therapies aimed at eradicating it. As MRD is a significant negative prognostic factor for relapse and survival in AML following allogeneic SCT, therapies capable of eliminating $M R D$ are urgently needed to increase the number of patients cured of their disease. Here, we have reviewed the most promising $\mathrm{MRD}$ targets with therapeutic potential based on efficacy in reducing MRD and potential for targeting leukemia repopulating cells mediating relapse. The targets discussed are by no means an exhaustive list and will continue to be refined as single-cell sequencing and xenograft studies better characterize leukemia populations in MRD that mediate relapse. Ultimately, incorporation of $\mathrm{MRD}$ into clinical practice will require pivotal trials that demonstrate an improvement in survival with MRD-directed approaches. Moving forward with MRD- targeted therapies will require a standardized method for detecting $M R D$ and rigorous assessment of the safety and efficacy of these therapies.

The European LeukemiaNet MRD working group has recently provided recommendations for assessment of MRD by multiparameter flow cytometry and molecular testing. ${ }^{2}$ These consensus recommendations aid the standardization of MRD testing should be incorporated into all AML clinical trials. Additional issues that will need to be addressed include the optimal timing of MRD assessments. MRD after induction, second induction and consolidation may have varying prognostic impact. Differences in time to initial response and the duration of response among MRD therapies may also affect the interval of MRD assessments. In particular, IDH inhibitors typically take a longer time to produce an initial response and may warrant later MRD assessments at later timepoints than MRD therapies with a faster onset of effect.

The use of MRD as a surrogate endpoint for survival for clinical trials in AML has the potential to accelerate drug development. Although MRD has a significant impact on prognosis, the mortality associated with treating MRD also needs to be considered. The experience with CD33targeted therapies demonstrates that toxicities associated with treatment may outweigh the potential benefit associated with eradicating $M R D$. In addition, $M R D$ as a surrogate endpoint would not capture the impact of $M R D$ therapies on transplant outcomes. For example, vadastuximab and GO were associated with an increased risk of veno-occlusive disease after transplantation. T-cell-activating therapies such as checkpoint inhibitors, dendritic cell vaccines and CAR-T cells have the potential to increase the risk of graft-versus-host disease after transplantation. Therefore, initial studies evaluating the safety of MRD-directed therapies should include post-transplant outcomes to identify late toxicities. The development of $M R D$-directed therapies may be facilitated in other ways. Similar to clinical trials in acute lymphoblastic leukemia and pediatric AML, current and future clinical trials in patients with AML who are fit for allogeneic SCT should include an intensification arm with MRD-directed therapies. This has the potential to increase the number of trials evaluating MRD therapies.

\section{References}

1. Yates JW, Wallace HJ Jr, Ellison RR, Holland JF. Cytosine arabinoside (NSC-63878) and daunorubicin (NSC-83142) therapy in acute nonlymphocytic leukemia. Cancer Chemother Rep. 1973;57(4):485-488.

2. Schuurhuis GJ, Heuser M, Freeman S, et al. Minimal/measurable residual disease in AML: a consensus document from the European LeukemiaNet MRD Working Party. Blood. 2018;131(12):1275-1291.

3. Freeman SD, Hills RK, Virgo $\mathrm{P}$, et al. Measurable residual disease at iduction redefines partial response in acute myeloid leukemia and stratifies outcomes in patients at standard risk without NPM1 mutations. J Clin Oncol. 2018;36(15):14861497.

4. Buckley SA, Appelbaum FR, Walter RB. Prognostic and therapeutic implications of minimal residual disease at the time of transplantation in acute leukemia. Bone Marrow Transplant. 2013;48(5):630-641

5. Walter RB, Gyurkocza B, Storer BE, et al. Comparison of minimal residual disease as outcome predictor for AML patients in first complete remission undergoing myeloablative or nonmyeloablative allogeneic hematopoietic cell transplantation. Leukemia. 2015;29(1):137-144.

6. Araki D, Wood BL, Othus $M$, et al. Allogeneic hematopoietic cell transplantation for acute myeloid leukemia: time to move toward a minimal residual diseasebased definition of complete remission? J Clin Oncol. 2016;34(4):329-336.

7. Kayser S, Benner A, Thiede C, et al. Pretransplant NPM1 MRD levels predict outcome after allogeneic hematopoietic stem cell transplantation in patients with acute myeloid leukemia. Blood Cancer J. 2016;6:e449.
8. Terwijn M, Putten WLJv, Kelder A, et al High prognostic impact of flow cytometric minimal residual disease detection in acute myeloid leukemia: data from the HOVON/SAKK AML 42A study. J Clin Oncol. 2013;31(31):3889-3897.

9. Maurillo L, Buccisano F, Del Principe MI, et al. Toward optimization of postremission therapy for residual disease-positive patients with acute myeloid leukemia. J Clin Oncol. 2008;26(30):4944-4951.

10. Kreso A, Dick John E. Evolution of the cancer stem cell model. Cell Stem Cell. 2014;14(3):275-291.

11. Lapidot T, Sirard C, Vormoor J, et al. A cell initiating human acute myeloid leukaemia after transplantation into SCID mice. Nature. 1994;367(6464):645-648.

12. Shlush LI, Mitchell A, Heisler L, et al. Tracing the origins of relapse in acute myeloid leukaemia to stem cells. Nature. 2017;547(7661):104-108. 
Promising targets for MRD therapies in AML

13. Papaemmanuil E, Gerstung M, Bullinger L, et al. Genomic classification and prognosis in acute myeloid leukemia. $N$ Engl J Med. 2016;374(23):2209-2221.

14. Frohling S, Schlenk RF, Breitruck J, et al. Prognostic significance of activating FLT3 mutations in younger adults (16 to 60 years) with acute myeloid leukemia and normal cytogenetics: a study of the AML Study Group Ulm. Blood. 2002;100(13):4372-4380.

15. Navel G, Weber D, Fromm E, et al. Epidemiological, genetic, and clinical characterization by age of newly diagnosed acute myeloid leukemia based on an academic population-based registry study (AMLSG BiO). Ann Hematol. 2017;96(12):1993-2003.

16. Thiede C, Strudel C, Mohr B, et al. Analysis of FLT3-activating mutations in 979 patients with acute myelogenous leukemia: associatron with FAB subtypes and identification of subgroups with poor prognosis. Blood. 2002;99(12):4326-4335

17. Kottaridis PD, Gale RE, Frow ME, et al. The presence of a FLT3 internal tandem duplicaton in patients with acute myeloid leukemia (AML) adds important prognostic information to cytogenetic risk group and response to the first cycle of chemotherapy: analysis of 854 patients from the United Kingdom Medical Research Council AML 10 and 12 trials. Blood. 2001;98(6):17521759.

18. Sengsayadeth SM, Jagasia M, Engelhardt BG, et al. Allo-SCT for high-risk AML-CR1 in the molecular era: impact of FLT3/ITD outweighs the conventional markers. Bone Marrow Transplant. 2012;47(12):1535-1537.

19. Perl A, Martinelli, G, Cortes, JE, et al. Gilteritinib significantly prolongs overall survivas in patients with FLT3-mutated (FLT3mut+) relapsed/refractory (R/R) acute myeloid leukemia (AML): results from the phase III ADMIRAL trial Abstract \#CCT184. Presented at the American Association for Cancer Research Annual Meeting 2019.

20. Levis M, Perl, AE, Altman, JK, et al. Impact of minimal residual disease and achievemont of complete remission/complete remission with partial hematologic recovery (CR/CRh) on overall survival following treatment with gilteritinib in patients with relapsed/refractory (R/R) acute myeloid leukemia (AML) with FLT3 mutations. Blood. 2018;132.

21. Cortes J, Perl, AE, Dohner, H, et al. Quizartinib, an FLT3 inhibitor, as monotherany in patients with relapsed or refractory acute myeloid leukaemia: an open-label, multicentre, single-arm, phase 2 trial. Lancet Oncol. 2018;19(7):889-903.

22. Proper DJ, McDonald AC, Man A, et al. Phase I and pharmacokinetic study of PKC412, an inhibitor of protein kinase C. J Chin Oncol. 2001;19(5):1485-1492.

23. Stone RM, Mandrekar SJ, Sanford BL, et al. Midostaurin plus chemotherapy for acute myeloid leukemia with a FLT3 mutation. N Engl J Med. 2017;377(5):454-464.

24. Stone RM, Mandrekar SJ, Sanford BL, et al. The addition of midostaurin to standard chemotherapy decreases cumulative incidance of relapse (CIR) in the international prospective randomized, placebo-controlled, double-blind trial (CALGB 10603 / RATIFY [Alliance]) for newly diagnosed acute myeloid leukemia (AML) patients with FLT3 mutations. Blood. 2017;130 (Suppl 1):2580.

25. Smith CC, Lin K, Stecula A, Sale A, Shah NP. FLT3 D835 mutations confer differential resistance to type II FLT3 inhibitors. Leukemia. 2015;29(12):2390-2392.

26. Wang E, Tallman M, Stone R, et al. Low relapse rate in younger patients $\leq 60$ years old with newly diagnosed FLT3-mutated acute myeloid leukemia (AML) treated with crenolanib and cytarabine/anthracycline chemotherapy. ASH Annual Meeting 2017. Blood. 2017;130(Suppl 1):566-566.

27. Stone R, Collins, R, Tallman, MS, et al. . Effect of cytarabine/anthracycline/ crenolanib induction on minimal residual disease (MRD) in newly diagnosed FLT3 mutant AML. ASCO Annual Meeting 2017. J Chin Oncol. 2017;35(15_suppl): 7016.

28. Pratz KW, Cherry M, Altman JK, et al. updated results from a phase 1 study of gilteritinib in combination with induction and consolidation chemotherapy in subjects with newly diagnosed acute myeloid leukemia (AML). ASH Annual Meeting 2018. 2018;132(Suppl 1):564.

29. Altman JK, Fran JM, Pratz KW, Throne D, Cortes JE, Tallman MS. Phase 1 study of quizartinib in combination with induction and consolidation chemotherapy in patients with newly diagnosed acute myeloid leukemia. Am J Hematol. 2018;93(2):213221.

30. Medeiros BC, Fath AT, DiNardo CD, Pollyea DA, Chan SM, Swords R. Isocitrate dehydrogenase mutations in myeloid malignancies. Leukemia. 2017;31(2):272-281.

31. Marcucci G, Maharry K, Wu YZ, et al. IDH1 and IDH2 gene mutations identify novel molecular subsets within de nov cytogenetically normal acute myeloid leukemia: a Cancer and Leukemia Group B study. J Chin Oncol. 2010;28(14):2348-2355.

32. Paschka P, Schlenk RF, Gaidzik VI, et al. IDH1 and IDH2 mutations are frequent genetic alterations in acute myeloid leukemia and confer adverse prognosis in cytogenetically normal acute myeloid leukemia with NPM1 mutation without FLT3 internal tandem duplication. J Chin Oncol. 2010;28(22):3636-3643.

33. Ward PS, Patel J, Wise DR, et al. The common feature of leukemia-associated IDH1 and IDH2 mutations is a neomorphic enzyme activity converting alpha-ketoglutarate to 2-hydroxyglutarate. Cancer Cell. 2010;17(3):225-234.

34. Mardis ER, Ding L, Dooling DJ, et al. Recurring mutations found by sequencing an acute myeloid leukemia genome. $\mathrm{N}$ Eng J Med. 2009;361(11):1058-1066.

35. Patel KP, Ravandi F, Ma D, et al. Acute myeloid leukemia with IDH1 or IDH2 mutation: frequency and clinicopathologic features. Am J Chin Pathol. 2011;135(1):3545.

36. Losman JA, Looper RE, Koivunen P, et al. (R)-2-hydroxyglutarate is sufficient to promote leukemogenesis and its effects are reversible. Science. 2013;339(6127):16211625.

37. Rats LM, Reschke M, Pauli R, et al. Protooncogenic role of mutant IDH2 in leukemia initiation and maintenance. Cell Stem Cell. 2014;14(3):329-341.

38. DiNardo CD, Ravandi F, Agresta S, et al. Characteristics, clinical outcome, and prognostic significance of IDH mutations in AML. Am J Hematol. 2015;90(8):732-736.

39. DiNardo CD, Stein EM, de Button S, et al. Durable remissions with ivosidenib in IDH1-mutated relapsed or refractory AML. N Encl J Med. 2018;378(25):2386-2398.

40. Stein EM, DiNardo CD, Pollyea DA, et al. Enasidenib in mutant IDH2 relapsed or

refractory acute myeloid leukemia. Blood. 2017;130(6):722-731.

41. Amatangelo MD, Quek L, Shin A, et al. Enasidenib induces acute myeloid leukemia cell differentiation to promote clinical response. Blood. 2017;130(6):732-741.

42. Stein E, DiNardo, CD, Fathi, AT, et al. Ivosidenib or enasidenib combined with induction and consolidation chemotherapy in patients with newly diagnosed AML with an IDH1 or IDH2 mutation is safe, effective, and leads to $\mathrm{MRD}$-negative complete remissons. ASH Annual Meeting. Blood. 2018:132(Suppl 1).

43. Schlenk RF, Weber D, Fiedler W, et al. Midostaurin added to chemotherapy and continued single-agent maintenance therapy in acute myeloid leukemia with FLT3-ITD. Blood. 2019;133(8):840.

44. Meta SV, Shula SN, Vera HH. Overexpression of $\mathrm{Bcl} 2$ protein predicts chemoresistance in acute myeloid leukemia: its correlation with FLT3. Neoplasma. 2013;60(6):666-675.

45. Luedtke DA, Nu X, Pan Y, et al. Inhibition of Mcl-1 enhances cell death induced by the Bcl-2-selective inhibitor ABT-199 in acute myeloid leukemia cells. Signal Transduct Target There. 2017;2:17012.

46. Lagadinou ED, Sech A, Callahan K, et al. BCL-2 inhibition targets oxidative phosphorylation and selectively eradicates quiescent human leukemia stem cells. Cell Stem Cell. 2013;12(3):329-341.

47. Pollyea DA, Stevens BM, Jones CL, et al. Venetoclax with azacitidine disrupts energy metabolism and targets leukemia stem cells in patients with acute myeloid leukemia. Nat Med. 2018;24(12):1859-1866.

48. Sours AJ, Leverson JD, Boghaert ER, et al. ABT-199, a potent and selective BCL-2 inhibitor, achieves antitumor activity while sparing platelets. Nat Med. 2013;19(2):202208.

49. Konopleva M, Pollyea DA, Potluri J, et al. Efficacy and biological correlates of response in a phase II study of venetoclax monotherapy in patients with acute myelogenous leukemia. Cancer Discov. 2016;6(10):11061117.

50. Wei A, Strickland, SA, Roboz, GJ, et al. Phase $1 / 2$ study of venetoclax with lowdose cytarabine in treatment-naive, elderly patients with acute myeloid leukemia unfit for intensive chemotherapy: 1-year outcomes. ASH Annual Meeting 2017. Blood. 2017;130(Suppl 1):890.

51. DiNardo CD, Pratz KW, Letai A, et al. Safety and preliminary efficacy of venetoclax with decitabine or azacitidine in elderly patients with previously untreated acute myeloid leukaemia: a non-randomised, open-label, phase $1 \mathrm{~b}$ study. Lancet Oncol. 2018;19(2):216-228.

52. Pollyea D, Pratz, KW, Jonas, BA, et al. Venetoclax in combination with hypomethylating agents induces rapid, deep, and durable responses in patients with AML ineligible for intensive therapy ASH Annual Meeting 2018.

53. Wei A, Strickland, SA, You, J, et al. Venetoclax with low-dose cytarabine induces rapid, deep, and durable responses in previously untreated older adults with AML ineligible for intensive chemotherapy ASH Annual Meeting 2018.

54. DiNardo C, Albitar, M, Kadia, TM, et al. Venetoclax in combination with FLAG-IDA chemotherapy (FLAG-V-I) for fit, relapsed/refractory AML patients: interim results of a phase $1 b / 2$ dose escalation and 
expansion study ASH Annual Meeting 2018. Blood. 2018;132(Suppl 1):4048.

55. Kastenhuber ER, Lowe SW. Putting p53 in context. Cell. 2017;170(6):1062-1078.

56. Zhao Z, Zuber J, Diaz-Flores E, et al. p53 loss promotes acute myeloid leukemia by enabling aberrant self-renewal. Genes Dev. 2010;24(13):1389-1402.

57. Kadia TM, Jain P, Ravandi F, et al. TP53 mutations in newly diagnosed acute myeloid leukemia: clinicomolecular characteristics, response to therapy, and outcomes. Cancer. 2016;122(22):3484-3491.

58. Hou HA, Chou WC, Kuo YY, et al. TP53 mutations in de novo acute myeloid leukemia patients: longitudinal follow-ups show the mutation is stable during disease evolution. Blood Cancer J. 2015;5:e331.

59. Rucker FG, Schlenk RF, Bullinger L, et al. TP53 alterations in acute myeloid leukemia with complex karyotype correlate with specific copy number alterations, monosomal karyotype, and dismal outcome. Blood. 2012;119(9):2114-2121

60. Bueso-Ramos CE, Yang Y, deLeon E, McCown P, Stass SA, Albitar M. The human MDM-2 oncogene is overexpressed in leukemias. Blood. 1993;82(9):2617-2623.

61. Li L, Tan Y, Chen X, et al. MDM4 overexpressed in acute myeloid leukemia patients with complex karyotype and wild-type TP53. PLoS One. 2014;9(11):e113088.

62. Karni-Schmidt O, Lokshin M, Prives C. The roles of MDM2 and MDMX in cancer. Annu Rev Pathol. 2016;11:617-644.

63. Ding Q, Zhang Z, Liu JJ, et al. Discovery of RG7388, a potent and selective p53-MDM2 inhibitor in clinical development. J Med Chem. 2013;56(14):5979-5983.

64. Goldberg A, Horvat, TZ, Hsu, M, et al. Venetoclax combined with either a hypomethylating agent or low-dose cytarabine shows activity in relapsed and refractory myeloid malignancies. ASH Annual Meeting 2017. Blood. 2017;130(Suppl 1):1353.

65. Aldoss I, Yang D, Aribi A, et al. Efficacy of the combination of venetoclax and hypomethylating agents in relapsed/refractory acute myeloid leukemia. Haematologica. 2018;103(9):e404-e407.

66. Lambert JM, Gorzov P, Veprintsev DB, et al. PRIMA-1 reactivates mutant p53 by covalent binding to the core domain. Cancer Cell. 2009:15(5):376-388.

67. Zhang Q, Bykov VJN, Wiman KG, Zawacka-Pankau J. APR-246 reactivates mutant p53 by targeting cysteines 124 and 277. Cell Death Dis. 2018;9(5):439.

68. Sallman D, DeZern, AE, Steensma, DP, et al. Phase 1b/2 combination study of APR-246 and azacitidine (AZA) in patients with TP53 mutant myelodysplastic syndromes (MDS) and acute myeloid leukemia (AML). ASH Annual Meeting 2018.

69. Fenaux P, Mufti GJ, Hellstrom-Lindberg E, et al. Efficacy of azacitidine compared with that of conventional care regimens in the treatment of higher-risk myelodysplastic syndromes: a randomised, open-label, phase III study. Lancet Oncol. 2009;10(3):223-232.

70. Kantarjian H, Issa JP, Rosenfeld CS, et al. Decitabine improves patient outcomes in myelodysplastic syndromes: results of a phase III randomized study. Cancer. 2006:106(8):1794-1803.

71. Dombret H, Seymour JF, Butrym A, et al. International phase 3 study of azacitidine vs conventional care regimens in older patients with newly diagnosed AML with $>30 \%$ blasts. Blood. 2015;126(3):291-299.

72. Hollenbach PW, Nguyen AN, Brady H, et al.
A comparison of azacitidine and decitabine activities in acute myeloid leukemia cell lines. PLoS One. 2010;5(2):e9001.

73. Ball B, Zeidan A, Gore SD, Prebet Hypomethylating agent combination strategies in myelodysplastic syndromes: hopes and shortcomings. Leuk Lymphoma. 2017;58(5):1022-1036.

74. Wolff F, Leisch M, Greil R, Risch A, Pleyer L. The double-edged sword of (re)expression of genes by hypomethylating agents: from viral mimicry to exploitation as priming agents for targeted immune checkpoint modulation. Cell Commun Signal. 2017;15(1):13.

75. Almstedt M, Blagitko-Dorfs N, DuqueAfonso J, et al. The DNA demethylating agent 5-aza-2'-deoxycytidine induces expression of NY-ESO-1 and other cancer/testis antigens in myeloid leukemia cells. Leuk Res. 2010;34(7):899-905.

76. Atanackovic D, Luetkens $\mathrm{T}$, Kloth B, et al Cancer-testis antigen expression and its epigenetic modulation in acute myeloid leukemia. Am J Hematol. 2011;86(11):918922.

77. Fonsatti E, Nicolay HJ, Sigalotti L, et al. Functional up-regulation of human leukocyte antigen class I antigens expression by 5 aza-2'-deoxycytidine in cutaneous melanoma: immunotherapeutic implications. Clin Cancer Res. 2007;13(11):33333338.

78. Chiappinelli KB, Strissel PL, Desrichard A, et al. Inhibiting DNA methylation causes an interferon response in cancer via dsRNA including endogenous retroviruses. Cell. 2015;162(5):974-986

79. Roulois D, Loo Yau H, Singhania R, et al. DNA-demethylating agents target colorectal cancer cells by inducing viral mimicry by endogenous transcripts. Cell. 2015;162(5): 961-973.

80. Yang H, Bueso-Ramos C, DiNardo C, et al. Expression of PD-L1, PD-L2, PD-1 and CTLA4 in myelodysplastic syndromes is enhanced by treatment with hypomethylating agents. Leukemia. 2014;28(6):1280-1288

81. Platzbecker U, Middeke JM, Sockel K, et al. Measurable residual disease-guided treatment with azacitidine to prevent haematological relapse in patients with myelodysplastic syndrome and acute myeloid leukaemia (RELAZA2): an open-label, multicentre, phase 2 trial. Lancet Oncol. 2018;19(12):1668-1679.

82. Khali DN, Smith EL, Brentjens RJ, Wolchok JD. The future of cancer treatment: immunomodulation, CARs and combination immunotherapy. Nat Rev Clin Oncol. 2016;13(5):273-290

83. Ribas A, Wolchok JD. Cancer immunotherapy using checkpoint blockade. Science. 2018:359(6382):1350-1355.

84. Berger R, Rotem-Yehudar R, Slama G, et al. Phase I safety and pharmacokinetic study of CT-011, a humanized antibody interacting with PD-1, in patients with advanced hematologic malignancies. Clin Cancer Res. 2008:14(10):3044-3051

85. Davids MS, Kim HT, Bachireddy P, et al. Ipilimumab for patients with relapse after allogeneic transplantation. $\mathrm{N}$ Engl J Med. 2016;375(2):143-153

86. Assi R, Kantarjian, HM, Daver, NG, et al. Results of a phase 2, open-label study of idarubicin (I), cytarabine (A) and nivolumab (Nivo) in patients with newly diagnosed acute myeloid leukemia (AML) and highrisk myelodysplastic syndrome (MDS). ASH Annual Meeting 2018. Blood. 2018;132 (Suppl 1):905
87. Daver N, Garcia-Manero G, Basu S, et al. Efficacy, safety, and biomarkers of response to azacitidine and nivolumab in relapsed/refractory acute myeloid leukemia: a nonrandomized, open-label, phase II study. Cancer Discov. 2019;9(3):370-383.

88. Weinstock M, Rosenblatt J, Avigan D Dendritic cell therapies for hematologic malignancies. Mol Ther Methods Clin Dev. 2017;5:66-75.

89. Sabado RL, Balan S, Bhardwaj N. Dendritic cell-based immunotherapy. Cell Res. 2017;27(1):74-95

90. Caux C, Vanbervliet B, Massacrier C, et al $\mathrm{B} 70 / \mathrm{B} 7-2$ is identical to CD86 and is the major functional ligand for CD28 expressed on human dendritic cells. J Exp Med. 1994;180(5):1841-1847.

91. Anguille S, Van de Velde AL, Smits EL, et al Dendritic cell vaccination as postremission treatment to prevent or delay relapse in acute myeloid leukemia. Blood. 2017;130 15):1713-1721.

92. Rosenblatt J, Stone RM, Uhl L, et al Individualized vaccination of AML patients in remission is associated with induction of antileukemia immunity and prolonged remissions. Sci Transl Med. 2016;8(368): 368ra171

93. Andrews RG, Takahashi M, Segal GM Powell IS, Bernstein ID, Singer JW. The L4F3 antigen is expressed by unipotent and multipotent colony-forming cells but not by their precursors. Blood. 1986;68(5):1030-1035.

94. Appelbaum FR, Bernstein ID. Gemtuzumab ozogamicin for acute myeloid leukemia. Blood. 2017;130(22):2373.

95. Walter RB, Appelbaum FR, Estey EH, Bernstein ID. Acute myeloid leukemia stem cells and CD33-targeted immunotherapy. Blood. 2012;119(26):6198-6208.

96. Krupka C, Kufer P, Kischel R, et al. CD33 target validation and sustained depletion of AML blasts in long-term cultures by the bispecific T-cell-engaging antibody AMG 330 Blood. 2014;123(3):356-365

97. Khan N, Hills RK, Virgo P, et al. Expression of CD33 is a predictive factor for effect of gemtuzumab ozogamicin at different doses in adult acute myeloid leukaemia. Leukemia. 2017;31(5):1059-1068.

98. Hamann PR, Hinman LM, Beyer CF, et al An anti-CD33 antibody-calicheamicin conjugate for treatment of acute myeloid leukemia. Choice of linker. Bioconjug Chem. 2002;13(1):40-46.

99. Bross PF, Beitz J, Chen G, et al. Approval summary: gemtuzumab ozogamicin in relapsed acute myeloid leukemia. Clin Cancer Res. 2001;7(6):1490-1496.

100. Petersdorf SH, Kopecky KJ, Slovak M, et al A phase 3 study of gemtuzumab ozogamicin during induction and postconsolidation therapy in younger patients with acute myeloid leukemia. Blood. 2013;121(24): 4854-4860.

101. Castaigne S, Pautas C, Terre C, et al. Effect of gemtuzumab ozogamicin on survival of adult patients with de-novo acute myeloid leukaemia (ALFA-0701): a randomised, open-label, phase 3 study. Lancet. 2012;379(9825):1508-1516.

102. Burnett AK, Hills RK, Milligan D, et al Identification of patients with acute myeloblastic leukemia who benefit from the addition of gemtuzumab ozogamicin: results of the MRC AML15 trial. J Clin Oncol. 2011;29(4):369-377.

103. Burnett AK, Russell NH, Hills RK, et al. Addition of gemtuzumab ozogamicin to induction chemotherapy improves survival in older patients with acute myeloid leukemia. 
Clin Oncol. 2012:30(32):3924-3931.

104. Hills RK, Castaigne S, Appelbaum FR, et al. Addition of gemtuzumab ozogamicin to induction chemotherapy in adult patients with acute myeloid leukaemia: a metaanalysis of individual patient data from randomised controlled trials. Lancet Oncol. 2014;15(9):986-996.

105. Burnett A, Cavenagh J, Russell N, et al. Defining the dose of gemtuzumab ozogamicin in combination with induction chemotherapy in acute myeloid leukemia: a comparison of $3 \mathrm{mg} / \mathrm{m} 2$ with $6 \mathrm{mg} / \mathrm{m} 2$ in the NCRI AML17 Trial. Haematologica. 2016;101(6):724-731.

106.Lambert J, Lambert J, Nibourel O, et al. MRD assessed by WT1 and NPM1 transcript levels identifies distinct outcomes in AML patients and is influenced by gemtuzumab ozogamicin. Oncotarget. 2014;5 (15):6280-6288

107. Laszlo GS, Gudgeon CJ, Harrington KH, et al. Cellular determinants for preclinical activity of a novel CD33/CD3 bispecific Tcell engager (BiTE) antibody, AMG 330, against human AML. Blood. 2014;123(4): 554-561.

108. Ravandi F, Stein, AS, Kantariian, HM, et al. A Phase 1 first-in-human study of AMG 330, an anti-CD33 bispecific T-cell engager (BiTE®) antibody construct, in relapsed/refractory acute myeloid leukemia (R/R AML) ASH Annual Meeting 2018.

109. Munoz L, Nomdedeu JF, Lopez O, et al. Interleukin-3 receptor alpha chain (CD123) is widely expressed in hematologic malignancies. Haematologica. 2001;86(12):12611269.

110. Jordan CT, Upchurch D, Szilvassy SJ, et al. The interleukin-3 receptor alpha chain is a unique marker for human acute myelogenous leukemia stem cells. Leukemia. 2000;14(10):1777-1784.

111. Kovtun Y, Jones GE, Adams S, et al. A
CD123-targeting antibody-drug conjugate, IMGN632, designed to eradicate AML while sparing normal bone marrow cells. Blood advances. 2018;2(8):848-858.

112. Daver NG, Erba HP, Papadantonakis N, et al. A phase I, first-in-human study evaluating the safety and preliminary antileukemia activity of IMGN632, a novel CD123-targeting antibody-drug conjugate, in patients with relapsed/refractory acute myeloid leukemia and other CD123-positive hematologic malignancies. ASH Annual Meeting 2018. Blood. 2018;132(Suppl 1):27.

113. Frankel AE, Woo JH, Ahn C, et al. Activity of SL-401, a targeted therapy directed to interleukin-3 receptor, in blastic plasmacytoid dendritic cell neoplasm patients. Blood. 2014:124(3):385-392.

114. Pemmaraju N, Lane AA, Sweet KL, et al. Tagraxofusp in blastic plasmacytoid dendritic-cell neoplasm. 2019;380(17):1628-1637.

115. van Rhenen A, van Dongen GAMS, Kelder A, et al. The novel AML stem cell-associated antigen CLL-1 aids in discrimination between normal and leukemic stem cells. Blood. 2007;110(7):2659.

116. Van Loo PF, Doornbos R, Dolstra $\mathrm{H}$ Shamsili S, Bakker L. Preclinical evaluation of MCLA117, a CLEC12AxCD3 bispecific antibody efficiently targeting a novel ukemic stem cell associated antigen in AML. Blood. 2015;126(23):325

117. June $\mathrm{CH}$, Sadelain M. Chimeric antigen receptor therapy. N Engl J Med. 2018;379 (1):64-73.

118. Ritchie DS, Neeson PJ, Khot A, et al. Persistence and efficacy of second generation CAR T cell against the LeY antigen in acute myeloid leukemia. Mol Ther. 2013:21(11):2122-2129.

119. Kenderian SS, Ruella M, Shestova O, et al. CD33-specific chimeric antigen receptor $T$ cells exhibit potent preclinical activity against human acute myeloid leukemia.
Leukemia. 2015·29(8):1637-1647.

120. Pizzitola I, Anjos-Afonso F, Rouault-Pierre K, et al. Chimeric antigen receptors agains CD33/CD123 antigens efficiently target primary acute myeloid leukemia cells in vivo. Leukemia. 2014;28(8):1596-1605

121. Gill S, Tasian SK, Ruella M, et al. Preclinical targeting of human acute myeloid leukemia and myeloablation using chimeric antigen receptor-modified $\mathrm{T}$ cells. Blood. 2014;123(15):2343-2354

122. Tashiro H, Sauer T, Shum T, et al. Treatment of acute myeloid leukemia with $T$ cells expressing chimeric antigen receptors directed to C-type lectin-like molecule 1 . Mo Ther. 2017;25(9):2202-2213.

123. Perna F, Berman SH, Soni RK, et al Integrating proteomics and transcriptomics for systematic combinatorial chimeric antigen receptor therapy of AML. Cancer Cell. 2017;32(4):506-519 e505.

124. Kim MY, Yu K-R, Kenderian SS, et al. Genetic inactivation of CD33 in hematopoietic stem cells to enable CAR $T$ cell immunotherapy for acute myeloid leukemia. Cell. 2018;173(6):1439-1453.e1419.

125. Khoury HI, Collins RH, Jr., Blum W, et al Immune responses and long-term disease recurrence status after telomerase-based dendritic cell immunotherapy in patient with acute myeloid leukemia. Cancer. 2017;123(16):3061-3072

126. van de Loosdrecht AA, van Wetering S, Santegoets S, et al. A novel allogeneic offthe-shelf dendritic cell vaccine for postremission treatment of elderly patients with acute myeloid leukemia. Cancer Immunol Immunother. 2018;67(10):1505-1518.

127. Lambert J, Pautas C, Terré C, et al. Gemtuzumab ozogamicin for de novo acute myeloid leukemia: final efficacy and safety updates from the open-label, phase III ALFA-0701 trial. Haematologica. 2019;104 (1):113. 